EPRA International Journal of Economic and Business Review-Peer Reviewed Journal

Volume - 9, Issue - 5, May 2021 | e-ISSN: 2347 - 9671| p- ISSN: 2349 - 0187

\title{
APPLICATION OF GEOGRAPHIC INFORMATION SYSTEMS IN MONITORING AGRICULTURAL LAND IN THE REPUBLIC OF UZBEKISTAN
}

\author{
Nafisa Abdurazakova \\ PhD, Tashkent Institute of Irrigation and Agricultural Mechanization Engineers, \\ Uzbekistan.
}

\begin{abstract}
DOI No: 10.36713/epra6697

Article DOI URL: https://doi.org/10.36713/epra6697

The presented article analyzes the topical issue of using geographic information systems in monitoring agricultural land in the Republic of Uzbekistan. Research methodology - analysis of scientific literature on a given problem, as well as practical domestic experience. The scientific novelty of the article lies in the demonstration of modern and relevant data on the land monitoring system within the framework of the agricultural industry on a specific example of a country - the Republic of Uzbekistan. As the main conclusions and results of the article, we can highlight the fact that Most of the economy of Uzbekistan is based on the development of the agricultural sector. In the field of agricultural production, high technologies are actively used here, namely, geographic information systems, which allow real-time collection of data on the area and other characteristics of agricultural land. So, systems based on GIS technologies have been used in the field of agricultural production since 2005. They collect and automatically process information on the turnover of agricultural land. As world practice shows, there are broad prospects for expanding the functionality of such systems. Thus, an integrated monitoring system allows you to plan the harvest and predict the amount of necessary fertilizers to be applied to the soil, analyze the effectiveness of agricultural work, etc. The integrated monitoring system is based on a map linking information about the location, area and boundaries of agricultural land. The results of the article are of theoretical and practical importance for modern science and can be recommended as citation in scientific papers.
\end{abstract}

KEY WORDS: information systems, agricultural land, commercial exploitation, monitoring, Republic of Uzbekistan.

\section{INTRODUCTION}

The introduction of a geographic information system in the agricultural sector in the republic took place at the beginning of the 2000s, when the work on defining the boundaries of municipalities was completed. The pilot project of the geoinformation monitoring system was launched in 2004, and already in 2005 the system was put into commercial operation.
At the preparatory stage (in the period 20002004), cartographic material was collected and digitized. At the first stage, GIS technologies were used to develop a system required for use by crop processing services (plowing, irrigation, fertilization and pest control with chemicals). Experience has shown that GIS technologies have almost unlimited possibilities for expanding functionality. Therefore, at the second stage of the project implementation, it was decided to develop an electronic map indicating 
the location and boundaries of agricultural enterprises located on the territory of the republic. In addition to vector maps, the system included semantic data (agroecological properties of agricultural plots).

Agricultural land fragmentation (ALF) is one of the main problems in developing countries, including Uzbekistan. ALF can affect agricultural production, rural development, labor supply, food security and land use change. Consequently, ALF governance should be a major component of land policy and decision-making systems for agricultural land. In Uzbekistan (as in many other countries), ALF has two main players: farmers and government. The main purpose of this study is to explain and assess the strategic decisionmaking space between farmer and government regarding the ALF problem in Uzbekistan using game theory. It is a strategic ALF game model based on the ordinal and cardinal preferences of the players. The results of this study show that in the normal form of play, the farmer tends to fragment his agricultural land, although the farmer's strictly dominant strategy is "not to fragment". The main reasons for the conflict include: a) the players in this game act in accordance with their best individual reaction and without considering the winnings of the entire system; b) players cannot create the necessary structures for cooperation; c) There is no external body to enforce the rules and regulations of the game. This study analyzes ALF play based on basic preferences, which is closer to the real world ALF. In terms of basic preferences, each player's best response is associated with at least four variables: the value of fragmented land (VF) and unfragmented land $(\mathrm{VN})$, punishment value $(\mathrm{PV})$, and reward value (EV). This study concludes that if the government or land policy makers want to manage ALF, they should not apply the same strategies to all agricultural land. The correct strategy for any type of land depends not only on their policy (PV and EV), but also on VF and VN.

\section{MATERIALS AND METHODS}

Since 2011, GIS technologies have been used to solve problems of remote monitoring of agricultural lands. Satellite imagery data, carried out in the period 2008-2009, made it possible to identify and identify land plots on the map. During the implementation of the project, a problem was identified with the discrepancy between the satellite imagery data and the data received from the cartographic service. In addition, a problem was identified with the impossibility of identifying small objects on the territory of sections. To detail the information, the method of imposing vector maps on satellite images was used. As a result of painstaking work, it was possible to create a full-scale electronic map showing basic information on land plots allocated for agricultural needs [1,9].

A contractor company was hired to develop a comprehensive monitoring system. Her task included the creation of an electronic map based on images from satellites and vector maps for clear detailing of individual objects on the map. As a result, satellite images were deciphered and compared with vector maps. The large-scale electronic map includes data on all agricultural land.

Today this system is used not only for remote monitoring, but also for changing the boundaries of the combined land plots. The electronic map in the integrated monitoring system presents data on the area of agricultural plots, data on their location space, data on the location of infrastructure facilities (buildings, structures, utilities and roads used) on the sites. An electronic map, in comparison with a vector map, has a high coordinate accuracy. Today, the republic has completed the work on correcting outdated vector maps. When referring to the integrated monitoring system, it should be noted that it includes detailed vector maps in electronic form and data from satellite images. On the map you can see the boundaries of agricultural plots and serial numbers within the same settlement. Each site has its own identification number $[2,5]$.

This system can be used in several directions at once. In particular, the system already contains a database with land plots, which shows the results of measurements along the boundaries and location of plots in space. These data are necessary for predicting the yield and planning agricultural processing, taking into account the fact that at different phases of development of crops, they require certain processing methods. A software solution for the constant acquisition of new satellite imagery data has been introduced into the integrated monitoring system. The data that enter the system is compared with the results of observations that are carried out from the ground. The system has uploaded data on agricultural crops grown on the territory of the republic. Their comparison with satellite imagery data and data based on the results of the work of ground services makes it possible to determine the phases of development of agricultural crops.

\section{RESULTS}

Comparison of data in different periods of time, starting from sowing, ending with the ripening of the crop, allows you to analyze the development of crops and make a forecast for yield in the current year. Data from meteorologists are used as auxiliary data in the integrated monitoring system. This information is necessary in order to correct the forecast, as well as to choose the optimal time for carrying out certain agricultural works. To date, the problem is the frequent change in the boundaries of agricultural land. Therefore, monitoring of land use in terms of predicting soil fertility is complicated. Therefore, we are working with the owners of enterprises that are engaged in the cultivation of agricultural products. They need to 
adhere to a plan of action in order to maintain the level of soil fertility. Currently, work is underway to improve the geographic information system. This work is aimed at tracking fields, even with a small area, which, for example, belong to private farms [3, $6]$.

The operation of the system is based on data from space imagery. Already today, using space technologies, it is possible to identify over 30 types of crops grown. In the future, the monitoring system will be used to solve another problem - tracking the state of land taken out of agricultural use [4, 7]. Despite the obvious progress in computer technology, ground-based observational data are still relevant. In addition, for the monitoring system and the implementation of additional tasks on its basis, auxiliary data on the weather, used human resources and equipment are required [10, 11]. All this will make it possible to more accurately predict the volume of agricultural production. Based on the results of the study, it is necessary to conclude that the geoinformation monitoring system used in Uzbekistan has a wide functionality.

\section{CONCLUSIONS}

In particular, this system makes it possible to estimate the volume of cultivated areas, predict the yield of individual crops, and also assess the efficiency of the use of land resources. In the future, access to the system will be provided for private users as well. This will make it possible not only to estimate the volume of sown areas and predict the yield, but also to calculate the needs of a particular site and crops grown on it for the application of mineral fertilizers. In the meantime, commercial access to the system has been provided to agricultural producers. Large farms are already using it. The monitoring system helps them plan agricultural work, predict the harvest, as well as the removal of useful elements in the soil along with the harvest.

\section{LITERATURE}

1. Tkachenko S., Berezovska L., Protas O., Parashchenko L., Durmanov A. (2019). Social Partnership of Services Sector Professionals in the Entrepreneurship Education, Journal of Entrepreneurship Education, 22 (4), 6.

2. Umarov, SR, Durmanov, AS, Kilicheva, F.B, Murodov S.M., Sattorov OB (2019). Greenhouse Vegetable Market Development Based on the Supply Chain Strategy in the Republic of Uzbekistan, International Journal of Supply Chain Management (IJSCM), 8 (5).

3. Durmanov, $A S, L i, \quad M R$, Maksumkhanova AM, Khafizov, O. Kilicheva, FB and Rozikov J. (November, 2019). Simulation modeling, analysis and performance assessment. International Conference on Information Science and Communications Technologies ICISCT 2019, pg. 6.

4. Durmanov, AS, Tulaboev A., Li, MR, Maksumkhanova AM, Saidmurodzoda, $M M$ and Khafizov $O$. (November, 2019). Game theory and its application in agriculture (greenhouse complexes). International Conference on Information Science and Communications Technologies ICISCT 2019, pg. 6.

5. Gebeyehu, M. N. (2019). Remote Sensing and GIS Application in Agriculture and Natural Resource Management. International Journal of Environmental Sciences \& Natural Resources, 19(2). https://doi.org/10.19080/ijesnr.2019.19.556009

6. Iban, M. C., \& Aksu, O. (2020). A model for big spatial rural data infrastructure in Turkey: Sensordriven and integrative approach. Land Use Policy, 91. https://doi.org/10.1016/j.landusepol.2019.104376

7. Vibhute, A. D., \& Gawali, B. W. (2013). Analysis and Modeling of Agricultural Land use using Remote Sensing and Geographic Information System: Review. International Journal of Engineering Research and Applications, 3(3), 81-91.

8. Ozcelik, A. E., \& Nisanci, R. (2016). Land use patterns for driving environmental management of tea agricultural croplands. Computers and Electronics in Agriculture, 122, 41-54. https://doi.org/10.1016/j.compag.2016.01.013

9. Durmanov, A., Umarov, S., Rakhimova, K., Khodjimukhamedova, S., Akhmedov, A., \& Mirzayev, $S$. (2021). Development of the Organizational and Economic Mechanisms of Greenhouse Industry in the Republic of Uzbekistan. Journal of Environmental Management and Tourism, 12(2), 331-340. doi:10.14505//jemt. v12.2(50).03

10. Zhang, F., \& Cao, N. (2019). Application and research progress of Geographic Information System (GIS) in agriculture. In 2019 8th International Conference on Agro-Geoinformatics, AgroGeoinformatics 2019. Institute of Electrical and Electronics Engineers Inc. https://doi.org/10.1109/Agro-

Geoinformatics.2019.8820476

11. Nurimbetov, T., Umarov, S., Khafizova, Z., Bayjanov, S., Nazarbaev, O., Mirkurbanova, R., Durmanov, A. (2021). Optimization of the main parameters of the support-lump-breaking coil. Eastern-European Journal of Enterprise Technologies, 2 (1 (110)), 2736. https://doi.org/10.15587/1729-4061.2021.229184 